\title{
Surgical timing for cervical and upper thoracic injuries in patients with polytrauma
}

\author{
Daniel Lubelski, MD, ${ }^{1,5}$ Suzanne Tharin, MD, PhD, ${ }^{6}$ John J. Como, MD, MPH, ${ }^{2}$ \\ Michael P. Steinmetz, MD, ${ }^{1}$ Heather Vallier, MD, ${ }^{3}$ and Timothy Moore, MD ${ }^{3,4}$
}

\begin{abstract}
${ }^{1}$ Cleveland Clinic Lerner College of Medicine, Cleveland Clinic Center for Spine Health, and Department of Neurological Surgery, Cleveland Clinic, Cleveland; Departments of ${ }^{2}$ Surgery, ${ }^{3}$ Orthopaedic Surgery, and ${ }^{4}$ Neurosciences, MetroHealth Medical Center, Cleveland, Ohio; ${ }^{5}$ Department of Neurosurgery, Johns Hopkins Hospital, Baltimore, Maryland; and ${ }^{6}$ Department of Neurosurgery, Stanford University, Palo Alto, California
\end{abstract}

OBJECTIVE Few studies have investigated the advantages of early spinal stabilization in the patient with polytrauma in terms of reduction of morbidity and mortality. Previous analyses have shown that early stabilization may reduce ICU stay, with no effect on complication rates.

METHODS The authors prospectively observed 340 polytrauma patients with an Injury Severity Score (ISS) of greater than 16 at a single Level 1 trauma center who were treated in accordance with a protocol termed "early appropriate care," which emphasizes operative treatment of various fractures within 36 hours of injury. Of these patients, 46 had upper thoracic and/or cervical spine injuries. The authors retrospectively compared patients treated according to protocol versus those who were not. Continuous variables were compared using independent t-tests and categorical variables using Fisher's exact test. Logistic regression analysis was performed to account for baseline confounding factors.

RESULTS Fourteen of 46 patients $(30 \%)$ did not undergo surgery within 36 hours. These patients were significantly more likely to be older than those in the protocol group (53 vs 38 years, $p=0.008$ ) and have greater body mass index (BMl; 33 vs $27, p=0.02)$, and they were less likely to have a spinal cord injury (SCI) (82\% did not have an SCI vs $44 \%$ in the protocol group, $p=0.04$ ). In terms of outcomes, patients in the protocol-breach group had significantly more total ventilator days (13 vs 6 days, $p=0.02$ ) and total ICU days (16 vs 9 days, $p=0.03$ ). Infection rates were $14 \%$ in the protocol-breach group and $3 \%$ in the protocol group $(p=0.2)$ Total complications trended toward being statistically significantly more common in the protocol-breach group (57\% vs 31\%). After controlling for potential confounding variables by logistic regression (including age, sex, BMI, race, and $\mathrm{SCl}$ ), total complications were significantly $(p<0.05)$ greater in the protocol-breach group (OR 29,95\% Cl 1.9-1828). This indicates that the odds of developing "any complication" were 29 times greater if treatment was delayed more than 36 hours.

CONCLUSIONS Early surgical stabilization in the polytrauma patient with a cervical or upper thoracic spine injury is associated with fewer complications and improved outcomes. Hospitals may consider the benefit of protocols that promote early stabilization in this patient population.

https://thejns.org/doi/abs/10.3171/2017.4.SPINE16933

KEY WORDS polytrauma; cervical; thoracic; spinal cord injury; early treatment; trauma

$\mathrm{S}$ URGICAL management of polytrauma patients with unstable spinal injuries is challenging. These patients are frequently in critical condition, and there is no standard treatment paradigm on how to prioritize treatment of the numerous injuries. Furthermore, there are other factors that can delay treatment, including transportation, identification of type and extent of injuries, and availability of experienced spine surgeons. The implications of a delay in treatment are unclear.

Previous studies evaluating early versus late surgical stabilization for traumatic fractures have shown that early treatment is associated with a decreased stay in the ICU, reduced ventilator dependence duration and pulmonary complications, decreased hospital length of stay (LOS),

ABBREVIATIONS BMI = body mass index; EAC = early appropriate care; GCS = Glasgow Coma Scale; ISS = Injury Severity Score; LOS = length of stay; SCI = spinal cord injury. 
and an associated decrease in hospital costs. ${ }^{8,9,15,16}$ Some authors have also shown benefit in neurological outcomes associated with early stabilization. ${ }^{4}$ There have been differing results in the literature on overall complication rates following early versus late surgical stabilization, ${ }^{6}$ with some suggesting no difference between groups ${ }^{10,18}$ and others suggesting an advantage of early stabilization. ${ }^{4,5,8}$ The literature is even sparser regarding early versus late spinal stabilization in polytrauma patients. While there is consensus that early stabilization of long-bone fractures improves outcomes in polytrauma patients, there is little evaluation of early treatment of spinal fractures in this unique patient population.

In the present study, we sought to analyze the effect of early stabilization of spinal fractures in polytrauma patients. Our hypothesis was that early stabilization would be safe and effective, leading to reduced complications, shorter hospital stay, and superior outcomes.

\section{Methods}

This study was performed at MetroHealth Medical Center, which is affiliated with Case Western Reserve University, after IRB approval was granted. We retrospectively performed a subgroup analysis on patients with spinal injuries using data from a prospectively gathered database of 340 consecutive polytrauma patients at a single Level 1 trauma center who were treated according to a protocol we termed "early appropriate care" (EAC). The protocol has been previously described elsewhere. ${ }^{19-21}$ Briefly, the EAC protocol was applied to all patients with mechanically unstable fractures of the femur, pelvis, acetabulum, and/or spine requiring surgical stabilization, and data were collected between October 1, 2011, and March 31, 2014 (30 months). During this study period, polytrauma patients with an Injury Severity Score (ISS) of greater than 16 underwent operative treatment within 36 hours of injury once the patient met resuscitation requirements based on $\mathrm{pH}$, lactate, and base excess laboratory values. All included patients had an ISS of greater than 16 and at least one of the following: associated major injury to one or more body systems, hemodynamic instability, and immediate transfusion requirements due to injury. Patients were excluded if fractures were due to low-energy mechanism (e.g., fall from standing) or neoplasm, or if they were skeletally immature.

Within this larger cohort, 46 patients had cervical and upper thoracic spine injuries (anywhere between C-2 and $\mathrm{T}-2)$. We compared patients treated according to protocol with those who were not. Delays in operative intervention were most often because of physician choice for convenience. An adjudication committee consisting of anesthesiology, orthopedic surgery, neurosurgery, and trauma surgery personnel independently reviewed all patient records prospectively at 6-month intervals during the study period to assess if the EAC protocol was adhered to. None of the physicians in the adjudication committee were involved in the EAC steering committee or in data collection/analysis.

Patient information collected included age, sex, and body mass index (BMI). Clinical presentation data included ISS, Glasgow Coma Scale (GCS) score, extent and type of spinal injuries, and details of other injuries. Additionally, hospital and/or operative course, time to surgery, complications, and outcomes were determined.

All data were analyzed using JMP 9.0 (2007, SAS Institute Inc.). Descriptive statistics summarizing patient demographics were presented as the means and standard deviations or counts with percentages as appropriate. Continuous variables were compared using independent t-tests and categorical variables using Fisher's exact test. All $\mathrm{p}$ values $\leq 0.05$ were considered statistically significant. Logistic regression was performed to account for baseline confounding factors. Variables included in the logistic regression model were based on clinical indication or $\mathrm{p}$ value $<0.2$ on univariate analysis. Odds ratios and $95 \%$ confidence intervals were calculated.

\section{Results}

Forty-six patients were reviewed, including 14 (30\%) who did not undergo surgery within 36 hours (nonprotocol group) and $32(70 \%)$ who were treated per protocol within 36 hours (protocol group) (Table 1). All patients met the resuscitative criteria within 12 hours after presentation. Patients in the protocol group were significantly younger

TABLE 1. Demographic and presenting characteristics

\begin{tabular}{lccc}
\hline \multicolumn{1}{c}{ Variable } & $\begin{array}{c}\text { Protocol } \\
(<36 \mathrm{hrs})\end{array}$ & $\begin{array}{c}\text { Nonprotocol } \\
(6 \mathrm{hrs})\end{array}$ & $\begin{array}{c}\mathrm{p} \\
\text { Value* }\end{array}$ \\
\hline No. of patients & 32 & 14 & \\
\hline Mean age, yrs & $38.3 \pm 16.9$ & $53.3 \pm 16.0$ & 0.008 \\
\hline Female sex & $8(25)$ & $6(43)$ & 0.3 \\
\hline Mean BMl & $26.8 \pm 4.8$ & $32.6 \pm 10.8$ & 0.02 \\
\hline Race & & & 0.07 \\
Black & $9(28)$ & $1(7)$ & \\
White & $19(59)$ & $13(92)$ & \\
Other & $4(12)$ & $0(0)$ & \\
\hline Mechanism of injury & & & 0.05 \\
Fall & $12(38)$ & $2(14)$ & \\
Motor vehicle accident & $17(53)$ & $7(50)$ & \\
Motorcycle accident & $2(6)$ & $0(0)$ & \\
\hline Mean ISS & $25.7 \pm 10.6$ & $26.5 \pm 9.6$ & 0.8 \\
\hline Mean GCS score & $12.4 \pm 4.1$ & $9.5 \pm 5.8$ & 0.06 \\
\hline SCl & & & 0.04 \\
Complete & $4(16)$ & $2(18)$ & \\
Incomplete & $10(40)$ & $0(0)$ & \\
None & $11(44)$ & $9(82)$ & \\
\hline Cervical spine fracture $\dagger$ & $26(81)$ & $11(79)$ & 0.99 \\
\hline Loss of consciousness & $22(69)$ & $5(36)$ & 0.05 \\
\hline Mean no. of blood transfusions & $2.5 \pm 4.1$ & $5.7 \pm 7.3$ & 0.05 \\
\hline Mean total delay in treatment & $19.7 \pm 15.3$ & $71.4 \pm 42.1$ & $<0.0001$ \\
(hrs) & & & \\
\hline Valus are presented as the number & & \\
\hline
\end{tabular}

Values are presented as the number of patients (\%) unless stated otherwise. Mean values are presented \pm SD. Boldface type indicates statistical significance.

* Independent t-test for continuous variables, Fisher's exact test for categorical variables.

$\dagger$ Fractures that are not cervical spine fractures were located in the thoracic spine. 
( 38 vs 53 years, $\mathrm{p}=0.008$ ), had lower BMI ( 27 vs $33, \mathrm{p}=$ 0.02 ), and were more likely to have sustained a spinal cord injury (SCI) $(56 \%$ vs $18 \%, \mathrm{p}=0.04)$. The overall difference in time to treatment was a mean of 20 hours in the protocol group and 71 hours in the nonprotocol group ( $p$ $<0.0001$ ). There were no significant differences between groups based on sex, ISS, and GCS score at presentation. Furthermore, there were no differences between groups based on the type or extent of spinal injuries.

For the 14 patients who did not receive operative intervention within the 36-hour window, the majority of the delays were at the discretion of the operating surgeon or the intensivist ( 8 of 14 and 2 of 14 patients, respectively; Table $2)$. The reason for the delay by the primary provider was typically a matter of convenience in desiring to schedule the surgery for another day. The remaining surgeries were delayed for hemodynamic instability $(\mathrm{n}=1)$, requisite cardiac workup prior to operative intervention $(n=1)$, initial nonoperative treatment attempted $(\mathrm{n}=1)$, and lack of an available operating room $(\mathrm{n}=1)$.

After treatment, those in the nonprotocol group had significantly more total ventilator days (13 vs 6 days, $p$ $=0.02$ ) and total ICU days (16 vs 9 days, $\mathrm{p}=0.03$; Table $3)$. Infection rates were $14 \%$ in the nonprotocol group and $3 \%$ in the protocol group ( $\mathrm{p}=0.2)$. Total complications trended toward being significantly greater in the nonprotocol group $(57 \%$ vs $31 \%, \mathrm{p}=0.10)$.

After controlling for potential confounding variables by logistic regression (including age, sex, BMI, race, and SCI), the odds of total complications were significantly greater in the nonprotocol group (OR 29, 95\% CI 1.91828; $p=0.03)$. This indicates that the odds of developing "any complication" were 29 times greater when treatment was delayed for more than 36 hours.

\section{Discussion}

Almost half of all patients who experience a major trauma sustain spinal injuries. ${ }^{2}$ Despite the relatively high incidence in this patient population, there are no clinically

TABLE 2. Nonprotocol cohort: reasons for delay

\begin{tabular}{cl}
\hline Case No. & \multicolumn{1}{c}{ Reason for Delay } \\
\hline 1 & Surgeon's choice \\
\hline 2 & Nonsurgical initial attempt \\
\hline 3 & Surgeon's choice \\
\hline 4 & Surgeon's choice \\
\hline 5 & Cardiac workup \\
\hline 6 & No op room available \\
\hline 7 & Surgeon's choice \\
\hline 8 & Intensivist's choice \\
\hline 9 & Surgeon's choice \\
\hline 10 & Surgeon's choice \\
\hline 11 & Surgeon's choice \\
\hline 13 & Intensivist's choice \\
\hline 14 & Hemodynamically unstable \\
\hline
\end{tabular}

TABLE 3. Postoperative course

\begin{tabular}{lccl}
\hline \multicolumn{1}{c}{ Variable } & $\begin{array}{c}\text { Protocol } \\
(<36 \mathrm{hrs})\end{array}$ & $\begin{array}{c}\text { Nonprotocol } \\
(>36 \mathrm{hrs})\end{array}$ & $\begin{array}{c}\mathrm{p} \\
\text { Value* }\end{array}$ \\
\hline No. of patients & 32 & 14 & \\
\hline Mean ventilator days & $6.0 \pm 9.5$ & $13.2 \pm 9.2$ & $\mathbf{0 . 0 2}$ \\
\hline Mean ICU days & $8.8 \pm 10.1$ & $15.9 \pm 9.7$ & $\mathbf{0 . 0 3}$ \\
\hline Mean hospital LOS & $11.9 \pm 9.6$ & $17.9 \pm 8.8$ & $\mathbf{0 . 0 5}$ \\
\hline Overall complications & $10(31)$ & $8(57)$ & 0.1 \\
Pulmonary & $8(25)$ & $3(21)$ & 0.99 \\
Infection & $1(3)$ & $2(14)$ & 0.2 \\
Death & $2(6)$ & $3(21)$ & 0.2 \\
\hline
\end{tabular}

Values are presented as the number of patients (\%) unless stated otherwise. Mean values are presented \pm SD. Boldface type indicates statistical significance.

* Independent t-test for continuous variables, Fisher's exact test for categorical variables.

validated protocols to aid the surgeon in surgical timing for spinal injuries in the polytrauma patient. Proponents of delayed surgery argue that polytrauma patients may be too infirm to undergo the further physiological stress of surgery, which may lead to increased perioperative complications and worse outcomes. ${ }^{17}$ In contrast, others argue for early stabilization highlighting the concern of worsening spinal instability and/or associated neurological deficits that can occur when delaying needed surgical stabilization.

The EAC protocol enabled us to use objective data to determine when surgery is appropriate in polytrauma patients. Our data showed that early surgical stabilization $(<$ 36 hours) in the polytrauma patient with a cervical or upper thoracic spine injury leads to reduced complications and improved outcomes. These results are supported by previous studies in the trauma literature. While only few have investigated early versus late treatment in polytrauma patients, there are a number of investigations on patients with SCI and cervical and/or thoracic fractures.

In a single-cohort, prospective, longitudinal study, McLain and Benson ${ }^{11}$ monitored polytrauma patients with spinal fractures to determine whether urgent $(<24$ hours) surgical stabilization of the spine fractures increased the risk compared with early (24-72 hours) treatment. They found no complications in either group, and no revisions were needed in the urgent group. They concluded that urgent stabilization is safe in polytrauma patients, particularly in the setting of neurological deficit or fracture instability.

In a recent study by Bliemel et al., ${ }^{2}$ the authors analyzed data from the Trauma Registry of the German Trauma Society looking at polytrauma patients with spinal injuries. They compared early ( $<72$ hours) versus late $(>72$ hours) surgical treatment and found that early stabilization was associated with a shorter LOS, shorter ICU duration, and reduced rate of sepsis compared with those with late stabilization. Of note, those with worse ISSs were significantly more likely to be treated with early stabilization. While this latter point would likely increase the validity of the findings (i.e., despite worse presentation, outcomes are better in the early treatment group), the authors do not 
report using a logistic regression to account for possible confounding factors between the 2 cohorts.

Our study differs from the 2 previous reports ${ }^{2,11}$ in several ways. First, our patient data were collected from a prospectively gathered study specifically designed to assess early versus late stabilization. Second, we used logistic regression to account for potential confounding factors to determine the independent effect of early treatment. Last, the previous studies used different definitions of early and late treatment (24 and 72 hours, compared with 36 hours for early treatment in the present study). The trend among these studies, however, supports that early spinal stabilization in polytrauma patients may lead to superior perioperative outcomes with reduced ICU duration and LOS, as well as decreased complications. The study by McLain and Benson ${ }^{11}$ further demonstrates that early stabilization is not associated with increased long-term reoperation rates.

The data presented herein are also supported by similar previous studies that evaluated early versus late stabilization in isolated traumatic spinal fractures. Vaccaro and colleagues ${ }^{18}$ performed a randomized controlled trial comparing early ( $<72$ hours) versus late ( $>72$ hours) surgery in patients with cervical SCI and no other concurrent trauma or illness, and found that there were no significant differences in LOS, ICU duration, or neurological outcomes between the 2 groups. Cengiz et al. ${ }^{4}$ similarly performed a quasi-randomized controlled study of a small cohort and compared early ( $<8$ hours) and late (3-15 days) surgery for spinal fractures in patients with isolated thoracolumbar SCI. The authors reported that patients in the early surgery group had reduced complications, decreased ICU duration, shorter LOS, and superior neurological outcomes. Similar to the Vaccaro et al. trial, polytrauma patients were excluded.

Most of the prospective and large retrospective cohort studies in the literature have shown that early stabilization in spinal trauma patients is associated with decreased ICU duration, shorter LOS, and fewer complications. 1,3,7,9,12-14,22 Some authors ${ }^{5,15}$ have found that in patients presenting with greater severity injuries, as defined by higher ISS scores, the positive effect of early stabilization is increased. Chipman et al. ${ }^{5}$ reported that only in polytrauma patients (which they defined as ISS > 15) did early surgery lead to a significantly reduced ICU duration and complication rate. Similarly, Schinkel and Anastasiadis ${ }^{15}$ published that the most severely injured patients (ISS > 38) had the greatest benefit from early stabilization.

The 2 randomized studies in the literature comparing early versus late stabilization had small sample sizes and were not designed to answer questions about management of polytrauma patients. The prospective and retrospective cohort studies are limited in that they are subject to bias in the determination of whether a given patient will receive early or late surgery. The confounding variables include surgeon expertise and scheduling conflicts, as well as individual surgeon bias regarding preference for early or late stabilization in spinal trauma patients. Almost all of the studies have heterogeneous patient populations with a variety of spinal injuries; diverse associated neurological, thoracic, and abdominal injuries; different injury severi- ties; and a mix of baseline patient health status and comorbidities. The present study is not an exception, and interpretation of our results must be done with consideration of these limitations. Most of the studies in the literature, however, were not designed to investigate polytrauma patients, and many were not even designed to compare early versus late surgical stabilization but rather were done post hoc as a subanalysis of an existing data set. Our study is a part of a prospective protocol specifically evaluating early versus late spinal stabilization among polytrauma patients. We used multivariable logistic regression to control for confounding variables. This enabled us to conclude that early surgical stabilization is independently and significantly associated with reduced LOS, ICU duration, and complications. The wealth of data in similar studies, showing similar results, further validates our findings.

There are a number of limitations associated with the present study that should be considered. The primary weakness is that the patients could not be randomized into early or delayed operative groups. Therefore, while we used logistic regression to account for baseline confounders, there still is a possibility that some factors were not accounted for, leading to confounded results. It is possible that certain components of illness were not accounted for with ISS. Another limitation is the relatively small sample size and our inability to analyze patients based on fracture type or levels. Importantly, the small sample size included in this study precludes robust regression analysis. Statistical literature recommends 5-20 events/outcomes per candidate predictor variable. In the present study, we included 5 predictor variables for 18 events (less conservative than optimal). This was rationalized by the fact that these data are preliminary and observational and would certainly require further validation. Strengths of the study included the prospective design and the multidisciplinary development and implementation of the protocol institution-wide.

\section{Conclusions}

In polytrauma patients with cervical and/or upper thoracic spinal injuries, early surgical stabilization within 36-48 hours is recommended if possible. Partial/temporizing surgical stabilization may be considered in patients who cannot tolerate larger surgeries due to the extent of other injuries. Large, multicenter, randomized controlled trials, designed to evaluate this unique patient population, are needed to validate these findings.

\section{References}

1. Bellabarba C, Fisher C, Chapman JR, Dettori JR, Norvell DC: Does early fracture fixation of thoracolumbar spine fractures decrease morbidity or mortality? Spine (Phila Pa 1976) 35 (9 Suppl):S138-S145, 2010

2. Bliemel C, Lefering R, Buecking B, Frink M, Struewer J, Krueger A, et al: Early or delayed stabilization in severely injured patients with spinal fractures? Current surgical objectivity according to the Trauma Registry of DGU: treatment of spine injuries in polytrauma patients. J Trauma Acute Care Surg 76:366-373, 2014

3. Carreon LY, Dimar JR: Early versus late stabilization of spine injuries: a systematic review. Spine (Phila Pa 1976) 36:E727-E733, 2011 
4. Cengiz SL, Kalkan E, Bayir A, Ilik K, Basefer A: Timing of thoracolomber spine stabilization in trauma patients; impact on neurological outcome and clinical course. A real prospective (rct) randomized controlled study. Arch Orthop Trauma Surg 128:959-966, 2008

5. Chipman JG, Deuser WE, Beilman GJ: Early surgery for thoracolumbar spine injuries decreases complications. J Trauma 56:52-57, 2004

6. Dimar JR, Carreon LY, Riina J, Schwartz DG, Harris MB: Early versus late stabilization of the spine in the polytrauma patient. Spine (Phila Pa 1976) 35 (21 Suppl):S187-S192, 2010

7. Fehlings MG, Vaccaro A, Wilson JR, Singh A, W Cadotte D, Harrop JS, et al: Early versus delayed decompression for traumatic cervical spinal cord injury: results of the Surgical Timing in Acute Spinal Cord Injury Study (STASCIS). PLoS One 7:e32037, 2012

8. Kerwin AJ, Frykberg ER, Schinco MA, Griffen MM, Arce CA, Nguyen TQ, et al: The effect of early surgical treatment of traumatic spine injuries on patient mortality. J Trauma 63:1308-1313, 2007

9. Kerwin AJ, Frykberg ER, Schinco MA, Griffen MM, Murphy T, Tepas JJ: The effect of early spine fixation on nonneurologic outcome. J Trauma 58:15-21, 2005

10. Levi L, Wolf A, Rigamonti D, Ragheb J, Mirvis S, Robinson WL: Anterior decompression in cervical spine trauma: does the timing of surgery affect the outcome? Neurosurgery 29:216-222, 1991

11. McLain RF, Benson DR: Urgent surgical stabilization of spinal fractures in polytrauma patients. Spine (Phila Pa 1976) 24:1646-1654, 1999

12. McLain RF, Burkus JK, Benson DR: Segmental instrumentation for thoracic and thoracolumbar fractures: prospective analysis of construct survival and five-year follow-up. Spine J 1:310-323, 2001

13. O'Boynick CP, Kurd MF, Darden BV II, Vaccaro AR, Fehlings MG: Timing of surgery in thoracolumbar trauma: is early intervention safe? Neurosurg Focus 37(1):E7, 2014

14. Papadopoulos SM, Selden NR, Quint DJ, Patel N, Gillespie $\mathrm{B}$, Grube S: Immediate spinal cord decompression for cervical spinal cord injury: feasibility and outcome. J Trauma 52:323-332, 2002

15. Schinkel C, Anastasiadis AP: The timing of spinal stabilization in polytrauma and in patients with spinal cord injury. Curr Opin Crit Care 14:685-689, 2008

16. Schinkel C, Frangen TM, Kmetic A, Andress HJ, Muhr G: Timing of thoracic spine stabilization in trauma patients: im- pact on clinical course and outcome. J Trauma 61:156-160, 2006

17. Stahel PF, VanderHeiden T, Flierl MA, Matava B, Gerhardt D, Bolles G, et al: The impact of a standardized "spine damage-control" protocol for unstable thoracic and lumbar spine fractures in severely injured patients: a prospective cohort study. J Trauma Acute Care Surg 74:590-596, 2013

18. Vaccaro AR, Daugherty RJ, Sheehan TP, Dante SJ, Cotler JM, Balderston RA, et al: Neurologic outcome of early versus late surgery for cervical spinal cord injury. Spine (Phila Pa 1976) 22:2609-2613, 1997

19. Vallier HA, Dolenc AJ, Moore TA: Early appropriate care: a protocol to standardize resuscitation assessment and to expedite fracture care reduces hospital stay and enhances revenue. J Orthop Trauma 30:306-311, 2016

20. Vallier HA, Moore TA, Como JJ, Dolenc AJ, Steinmetz MP, Wagner KG, et al: Teamwork in trauma: system adjustment to a protocol for the management of multiply injured patients. J Orthop Trauma 29:e446-e450, 2015

21. Vallier HA, Wang X, Moore TA, Wilber JH, Como JJ: Timing of orthopaedic surgery in multiple trauma patients: development of a protocol for early appropriate care. J Orthop Trauma 27:543-551, 2013

22. Xing D, Chen Y, Ma JX, Song DH, Wang J, Yang Y, et al: A methodological systematic review of early versus late stabilization of thoracolumbar spine fractures. Eur Spine J 22:2157-2166, 2013

\section{Disclosures}

Dr. Steinmetz reports being a consultant for Intellirod, Globus, and Stryker and receiving royalties from Biomet.

\section{Author Contributions}

Conception and design: Moore, Lubelski. Acquisition of data: Moore, Como, Steinmetz, Vallier. Analysis and interpretation of data: all authors. Drafting the article: Lubelski. Critically revising the article: all authors. Reviewed submitted version of manuscript: all authors.

\section{Correspondence}

Timothy Moore, Department of Neurosciences, MetroHealth Medical Center, 2500 MetroHealth Dr., Cleveland, OH 44109. email: tmoore@metrohealth.org. 